\title{
Autonomic nervous system activity in patients with Fabry disease*
}

\author{
Eric Alamartine ${ }^{1 \#}$, Aurore Sury ${ }^{1}$, Frédéric Roche ${ }^{2}$, Vincent Pichot ${ }^{2}$, Jean-Claude Barthelemy ${ }^{2}$ \\ ${ }^{1}$ Department of Nephrology, Saint-Etienne University Hospital, Saint-Etienne, France \\ ${ }^{2}$ Department of Physiology, Saint-Etienne University Hospital, Saint-Etienne, France \\ Email: " eric.alamartine@univ-st-etienne.fr
}

Received 1 November 2011; revised 10 February 2012; accepted 6 March 2012

\begin{abstract}
Background: Fabry disease is an inherited, multisystemic and progressive lysosomal storage disorder. The first symptoms of Fabry neuropathy reflect progressive loss of function of both peripheral somatic and autonomic nerve cells. We aimed to evaluate autonomic nervous system (ANS) activity in a cohort of patients with Fabry disease. Methods: ANS activity was evaluated by determining heart rate variability, spontaneous baroreflex sensitivity and ambulatory blood pressure in 9 patients with Fabry disease. Possible correlations between ANS activity and clinical phenotype were investigated. Results: Indices of global activity were frequently high, while ANS balance was disturbed only in a few patients. Sympathetic nervous system parameters were within normal ranges, but indices of parasympathetic parameters were highly variable. Baroreflex sensitivity was significantly correlated with glomerular filtration rate. Conclusion: Distribution of ASN activity indices is wide in patients with Fabry disease. Autonomic imbalance has been associated with non-Fabry chronic kidney disease and cardiovascular risk. In Fabry disease, monitoring of ANS activity may contribute to comprehensive disease staging, and may be of value in identifying patients at high risk of developing renal and cardiac events.
\end{abstract}

Keywords: Fabry Disease; Autonomic Nervous System; Severity

\section{INTRODUCTION}

Fabry disease is an $\mathrm{X}$ chromosome-linked disorder of lipid metabolism caused by mutations in the gene encoding the enzyme $\alpha$-galactosidase A ( $\alpha$-Gal A) [1]. As a result of deficient or absent $\alpha$-Gal A activity, glycosphin-

\footnotetext{
*Disclosures: None.

${ }^{\#}$ Corresponding author.
}

golipids, in particular globotriaosylceramide $\left(\mathrm{Gb}_{3}\right)$, progressively accumulate within the lysosomes of a large variety of cell types. Affected cells include vascular endothelial cells, neural cells, renal cells and cardiomyocytes. A cascade of overlapping pathologic events leads to multisystemic disease manifestations with small fiber neuropathy-related symptoms (described later), angiokeratomata and eye abnormalities (e.g. cornea verticillata) often presenting in childhood [1]. Renal histological changes, including podocyte injury, and/or (micro) albuminuria may develop at young age [2-4]. Proteinuria is often first detected in the 2nd to 3rd decade of life and is strongly associated with decline in glomerular filtration rate (GFR) [5,6]. Left ventricular hypertrophy ( $\mathrm{LVH})$ is also a prominent feature in adults, particularly in males [7], and its extent correlates with the renal complications $[7,8]$. Other life-threatening complications include arrhythmias and early stroke [1,9]. Although disease presentation in heterozygous females is often more attenuated, a major proportion of affected women will develop significant morbidity [10]. If Fabry disease is suspected, the diagnosis can be confirmed by performing a bloodbased $\alpha$-Gal A assay (males) and/or Fabry mutation analysis (females) [1].

In Fabry disease, lipid storage in neural cells particularly affects small, unmyelinated nerve fibers and first symptoms reflect progressive loss of function in both peripheral somatic and autonomic nerve cells [11,12]. Fabry neuropathy clinically manifests as constant burning/tingling sensations in hands and feet, and acute, episodic pain triggered by illness, exercise, fever, stress or weather changes. Dysfunction of the autonomic nervous system (ANS; peripheral and central) accounts for impaired sweating, pupillary constriction and saliva and tear formation, gastrointestinal dysmotility, sensory losses, and diminished cutaneous flare with scratch. Baroreflex-mediated vasoconstriction can be deficient due to sympathetic vasomotor nerve fiber dysfunction [13]. Reduced heart rate acceleration upon exertion has 
been observed in young male patients and may result from cardiovagal dysfunction with parasympathetic and/or sympathetic nerve involvement [7,14]. In cases with advanced disease, it can lead to hypotension upon orthostatic challenge [13].

Available enzyme replacement therapies (ERTs; agalsidase alfa and agalsidase beta) can reduce or clear Gb3 deposits, reduce pain, stabilize kidney function and reduce left ventricular hypertrophy $[15,16]$. However, it has become clear that therapeutic outcomes are largely dependant on the disease severity at baseline highlighting the importance of comprehensive disease staging prior to start of ERT $[17,18]$. Symptoms resulting from ANS dysfunction substantially contribute to the burden of Fabry disease and assessing ANS activity can be an interesting complementary tool to quantify and monitor disease severity. We have evaluated ANS activity and possible correlations with clinical data in 9 patients with Fabry disease.

\section{MATERIAL AND METHODS}

\subsection{Patients}

Nine of the 11 patients with a confirmed diagnosis of Fabry disease followed at our nephrology department were included in the study. All patients gave informed consent prior to participation. Two patients declined to enter the study because of personal reasons. The study population included 5 males and 4 females with an average age ( $\pm \mathrm{SD}$ ) of $50.5 \pm 12.2$ years (range 24 - 64 years). Measurement of $\alpha$-Gal A enzyme activity and Fabry mutation analysis (Biochemistry Laboratory, Hospices Civils de Lyon, France) had been performed in all patients following clinical suspicion of Fabry disease, or as part of screening of the family of a confirmed patient. Renal function was assessed by measurement of 24-hour proteinuria and inulin clearance. All 6 patients with proteinuria had undergone renal biopsy to document structural changes (Laboratoire d'Explorations Fonctionnelles Rénales, University Hospital Saint Etienne, France) and to enable informed treatment decisions. Cardiac evaluation included 12-lead electrocardiography and transthoracic echocardiography. Eight out of 9 patients received ERT with agalsidase beta and 6 received renoprotective treatment with an angiotensin-converting enzyme inhibitor (ACEI). ANS tests were done after start of ERT and ACEI.

\subsection{Autonomic Nervous System (ANS) Activity Measurements}

ANS activity measurements included assessment of heart rate variability (HRV), spontaneous baroreflex sensitivity (BRS), and ambulatory blood pressure monitoring
(AMBP).

HRV was measured using 24-hour Holter monitoring (Vista, Duosft, Novacor, Rueil-Malmaison, France). Each RR interval was manually validated before analysis. Then, HRV indices were calculated for the 24-hour period and, additionally, for the day and night periods. Over these last periods, the mean RR, time domain, and frequency indices were calculated using Fourier and Wavelet transform of HRV. All indices were calculated using published standards $[19,20]$ widely recognized as indices providing a good estimation of ANS activity. Some variables issued from the time domain analysis are mainly under the control of parasympathetic activity (PNN50, RMSSD) or sympathetic activity (SDNN, SDANN) [21]. The indices corresponding to the very low frequency of the spectrum (VLF) relate to parasympathetic activity, low frequency indices (LF) relate to both sympathetic and parasympathetic activities. High frequency (HF) represents the vagal activity, and the LF/HF ratio estimates ANS balance [22,23]. The very low frequency index (VLFI) is a marker of sleep fragmentation, and is mostly associated to sleep apnea. Using the frequency analysis, the total power of the spectrum (Ptot) is an estimation of the global activity of the ANS.

Spontaneous cardiac BRS was calculated using the sequences method [24] and the cross-spectral analysis method [21]. A 15-minute simultaneous recording of the electrocardiogram, blood pressure and ventilation was performed at rest in the supine position. Finger arterial blood pressure was measured using a noninvasive continuous blood pressure monitor (Finapress 2300, Ohmeda). The plethysmographic cuff was placed around the middle phalanx of the finger and the cuff pressure was modulated to maintain transmural pressure at zero. Then, RR intervals were calculated and each RR interval was paired with the corresponding systolic pressure wave. To determine spontaneous cardiac BRS, the linear regression slope was calculated for each sequence of at least three or more successive heart beats in which there were concordant increases or decreases in systolic blood pressure and RR interval. Cardiac BRS (expressed in milliseconds per millimeter of mercury) was calculated as the mean of the slopes of all sequences. The cross-spectral analysis method was used on the same recordings. BRS was calculated as the ratio between the transfer function moduli of arterial blood pressure and HRV, for the frequencies between 0.04 and $0.15 \mathrm{~Hz}\left(\mathrm{a}_{\mathrm{LF}}\right)$ and between 0.15 and $0.40 \mathrm{~Hz}\left(\mathrm{a}_{\mathrm{HF}}\right)$. The value was considered to be validated when the coherence between arterial blood pressure and HRV was greater than 0.5.

Ambulatory systolic arterial blood pressure (SBP), diastolic arterial blood pressure (DBP), and mean arterial blood pressure (MBP) were assessed using a 24-hour ambulatory Holter recorder based on the auscultatory 
method (Diasys Integra, Novacor, Rueil-Malmaison, France).

\subsection{Statistics}

The data were analyzed using the SPSS software.

\section{RESULTS}

Demographic data and clinical characteristics at time of ANS activity evaluation are presented in Table 1. Peripheral pain and hypohidrosis were reported by all patients. Six patients in the age range of 43 to 64 years all had CKD, cardiac hypertrophy, and one had severe neurovascular disease. Of the other patients, one young adult male who had no residual enzyme activity had been identified through family screening (patient 1) and had yet no signs of organ complications. In contrast, a 62year-old female patient (patient 9) had 50\% residual enzyme activity despite a large GLA gene deletion. She had been diagnosed at 30 years old and had progressed to end-stage renal disease (ESRD) necessitating kidney transplantation at age 41. Her respiratory insufficiency was believed to be due to Fabry disease. A third patient (patient 4, 51-year-old female, 30\% residual activity) only had a cardiac conduction abnormality and was not commenced on ERT.

Table 2 presents the autonomic nervous system activity indices. Sympathetic activity was conserved, as indicated by normal SDNN (mean $136.2 \pm 46.3 \mathrm{~ms}$ ) and SDANN (mean $91.0 \pm 48.3 \mathrm{~ms}$ ) values. Although the mean LF/HF ratio $(2.96 \pm 2.29)$ was found within the expected range, the results from 3 patients were suggestive of ANS disbalance. The parasympathetic activity, however, varied widely with pNN50 ranging from $1.8 \%$ to $46.8 \%$, HF from 36 to $4009 \mathrm{msec}^{2} / \mathrm{Hz}$, and BRS from 0.69 to 19.78 $\mathrm{ms} / \mathrm{mmHg}$. The LF/HF ratio spanned from 0.91 to 7.66 . The VLFI index was frequently elevated, up to 6.90, and the value was above the threshold of 4.2 in 3 patients.

A single patient (patient 9) had a very low Ptot, as assessed by temporal analysis, and low sympathetic and parasympathetic indices (Fourier transform) with a LF/ HF ratio reaching 1.92 and a severely depressed BRS slope value. This particular patient had progressed to ESRD. The youngest patient had no signs of organ failure and exhibited the highest Ptot and BRS.

Blood pressure values were relatively low in all patients necessitating careful titration of ACEI therapy (6 patients) to avoid hypotensive side effects. Mean systolic blood pressure was $103 \pm 10 \mathrm{mmHg}$ and mean diastolic blood pressure $66 \pm 5 \mathrm{mmHg}$.

In this small population, a significant positive correlation was found between glomerular filtration rate (GFR) and BRS ( $p<0.05 ; r=0.75$, Figure 1), while there were no correlations with other ANS variables. Gender, age, proteinuria, left ventricular mass and arterial blood pressure all did not significantly correlate with ANS indices. However, there was a tendency for the severity of proteinuria to correlate with left ventricular mass $(r=0.66$; $p$ $=0.051)$.

\section{DISCUSSION}

We describe the results of quantitative measurements of ANS in 9 patients with Fabry disease. ANS indices (HRV, spontaneous BRS, and ambulatory blood pressure), analyzed using established methods [19-21,24], varied considerably between the individuals. The indices of global

Table 1. Demographics and clinical characteristics of 9 patients with Fabry disease.

\begin{tabular}{|c|c|c|c|c|c|c|c|c|c|c|}
\hline Patient & Sex & Age & $\begin{array}{c}\alpha \text {-galactosidase } \\
\text { A activity }\end{array}$ & $\begin{array}{c}\text { GLA } \\
\text { mutation }\end{array}$ & $\begin{array}{c}\text { Proteinuria } \\
\text { g/24H }\end{array}$ & 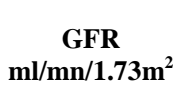 & $\begin{array}{l}\text { Conduction } \\
\text { disorder }\end{array}$ & $\begin{array}{l}\text { Left ventricular } \\
\text { mass } \mathbf{g} / \mathrm{m}^{2}\end{array}$ & Various & $\begin{array}{c}\text { Enzyme } \\
\text { replacement } \\
\text { therapy }\end{array}$ \\
\hline 1 & M & 25 & $0 \%$ & N224D & 0 & 122 & $\mathrm{~N}$ & 68 & & $\mathrm{Y}$ \\
\hline 2 & $\mathrm{~F}$ & 64 & $29 \%$ & N224D & 0.45 & 71 & $\mathrm{Y}$ & 147 & & $\mathrm{Y}$ \\
\hline 3 & M & 49 & $0 \%$ & R227X & 0.48 & 80 & $\mathrm{Y}$ & 100 & & $\mathrm{Y}$ \\
\hline 4 & $\mathrm{~F}$ & 51 & $30 \%$ & R227X & 0 & 100 & $\mathrm{Y}$ & 90 & & $\mathrm{~N}$ \\
\hline 5 & M & 51 & $0 \%$ & c89delG & 0.70 & 65 & $\mathrm{Y}$ & 150 & & $\mathrm{Y}$ \\
\hline 6 & $\mathrm{~F}$ & 63 & $4 \%$ & R227X & 1.50 & 85 & $\mathrm{Y}$ & 288 & stroke & $\mathrm{Y}$ \\
\hline 7 & M & 43 & $0 \%$ & c89delG & 2.30 & 100 & $\mathrm{Y}$ & 279 & & $\mathrm{Y}$ \\
\hline 9 & $\mathrm{~F}$ & 62 & $50 \%$ & $\begin{array}{c}\text { Large } \\
\text { deletion }\end{array}$ & 0 & 29 & $\mathrm{~N}$ & 92 & $\begin{array}{c}\text { respiratory } \\
\text { insufficiency }\end{array}$ & $\mathrm{Y}$ \\
\hline
\end{tabular}

GFR is glomerular filtration rate, $\mathrm{Y}$ is yes, $\mathrm{N}$ is no. 
Table 2. Autonomic nervous system activity indices in 9 patients with Fabry disease.

\begin{tabular}{|c|c|c|c|c|c|c|c|c|c|c|c|c|}
\hline Indices & Units & normal values & 1 & 3 & 3 & 4 & 5 & 6 & 7 & 8 & 9 & $\mathrm{~m} \pm \mathrm{SD}$ \\
\hline \multicolumn{13}{|l|}{$\begin{array}{c}\text { Heart rate } \\
\text { variability HRV }\end{array}$} \\
\hline \multicolumn{13}{|l|}{$\begin{array}{l}\text { Temporal analysis } \\
\text { (nocturnal) }\end{array}$} \\
\hline SDNN & msec & $50-150$ & 201.9 & 179.4 & 134.4 & 80.2 & 104.8 & 100.8 & 127.8 & 199.9 & 97.4 & $136.2 \pm 4.3$ \\
\hline pNN50 & $\%$ & $>11 \%$ & 46.8 & 24.3 & 28.5 & 11.9 & 6.9 & 48.3 & 9.5 & 4.3 & 1.8 & $20.2 \pm 17.7$ \\
\hline SDANN & msec & $50-150$ & 148 & 126 & 45 & 54 & 60 & 48 & 72 & 178 & 88 & $91.0 \pm 48.3$ \\
\hline \multicolumn{13}{|l|}{ Fourier transform } \\
\hline Ptot & $\mathrm{msec}^{2} / \mathrm{Hz}$ & $3500-4500$ & 9770 & 7216 & 6578 & 2324 & 4060 & 5535 & 4695 & 1555 & 590 & $4702 \pm 2938$ \\
\hline $\mathrm{HF}$ & $\mathrm{msec}^{2} / \mathrm{Hz}$ & $50-100$ & 1201 & 4009 & 773 & 190 & 102 & 1468 & 179 & 157 & 36 & $901 \pm 1277$ \\
\hline LF & $\mathrm{msec}^{2} / \mathrm{Hz}$ & $200-360$ & 1446 & 844 & 1985 & 630 & 707 & 1195 & 869 & 264 & 62 & $889 \pm 589$ \\
\hline \multicolumn{13}{|l|}{ sleep apnea } \\
\hline VLFI & $\%$ & $<4.2$ & 2.21 & 0.15 & 1.81 & 2.84 & 6.84 & 0.22 & 6.9 & 3.45 & 4.99 & $3.26 \pm 2.53$ \\
\hline \multicolumn{13}{|l|}{ Baroreflex BRS } \\
\hline nocturnal slope & $\mathrm{ms} / \mathrm{mmHg}$ & $>10$ & 19.78 & 13.59 & 12.99 & 16.30 & 6.57 & 18.59 & 11.99 & 9.26 & 0.69 & $12.79 \pm 6.57$ \\
\hline \multicolumn{13}{|l|}{$\begin{array}{l}24 \mathrm{H} \text { blood pressure } \\
\text { AMBP }\end{array}$} \\
\hline cardiac frequency & $/ \mathrm{mn}$ & & 68 & 60 & 59 & 60 & 66 & 67 & 64 & 86 & 83 & $70.1 \pm 9.8$ \\
\hline SBP & $\mathrm{mmHg}$ & & 111 & 98 & 96 & 97 & 107 & 100 & 103 & 126 & 92 & $103.3 \pm 10.2$ \\
\hline DBP & $\mathrm{mmHg}$ & & 67 & 65 & 59 & 66 & 65 & 72 & 62 & 74 & 65 & $66.1 \pm 4.5$ \\
\hline MBP & $\mathrm{mmHg}$ & & 75 & 73 & 71 & 76 & 78 & 81 & 75 & 91 & 74 & $77.1 \pm 5.9$ \\
\hline
\end{tabular}

High values are in italics, low values are in bold.



Figure 1. Correlation between baroreflex and glomerular filtration rate $(\mathrm{p}<0.05 ; \mathrm{r}=0.75)$. activity (Ptot, and in particular LF) were frequently high, while ANS balance was disturbed only in a few patients as indicated by an abnormal LF/HF ratio. Although sympathetic nervous system parameters (SDNN, SDANN) were within normal ranges, indices of parasympathetic parameters (i.e. pNN50, HF, BRS) were highly variable in our cohort.

Hilz et al. have previously reported that baroreflexmediated vasoconstriction can be deficient in patients with Fabry disease due to sympathetic vasomotor nerve fiber dysfunction [13]. In our study, BRS values were found to be strongly correlated with GFR. Neither sex nor age was associated with parasympathetic activity and there was no association with cardiac hypertrophy or rhythm abnormalities. Deficient BRS in relation with decline in GFR has been previously described in patients with chronic renal failure, regardless of the underlying renal disorder [25]. Sympathetic nervous system activation of the sympathetic nervous system has been reported to be an important feature contributing to renal injury 
[26-29], in part through its concomitant adverse effects on hypertension [30]. Six of our patients had CKD and had undergone kidney biopsy showing typical Gb3 deposition in the mesangial cells, endothelial cells and in podocytes. Yet, sympathetic nervous system indices were normal in all patients and blood pressures were low. Of note, systemic blood pressure has been found above the target level of 130/80 mmHg in substantial proportions of patients with Fabry disease [17].

HRV indices varied considerably in our patients. Decreased HRV has been reported in young patients with Fabry disease and is believed to reflect a reduction in parasympathetic stimulation of the heart [7]. Longitudinal studies in the general population have documented the predictive value of low HRV for an adverse cardiac prognosis [31,32]. In particular, reduced ANS activity evaluated through HRV indices were independently associated with an increased risk of myocardial infarction, congestive heart failure, death from cardiovascular disease, and total mortality [31-33].

Little is known about the mechanisms underlying disturbances of ANS activity in Fabry disease, but multiple factors are believed to contribute to ischemic neural damage, including narrowing of neural small blood vessels due to vascular endothelial $\mathrm{Gb}_{3}$ storage, loss of smooth muscle resiliency, and thrombotic complications [34]. A recent questionnaire study used the Autonomic Symptom Profile to prospectively evaluate ANS activity in 48 Fabry patients [35]. The investigators disputed the role of neuropathy in Fabry-related autonomic dysfunction based on their findings which included a low prevalence of orthostatic intolerance and normal cardiovascular autonomic function. Therefore, they dispute the role of neuropathy in Fabry-related autonomic dysfunction, and suggest a key role of organ failure was suggested to play a key role in development of signs of autonomic dysfunction. Of note, a patient questionnaire is a disputable method of quantifying ANS activity.

Currently, there is no undisputable biomarker for disease burden of phenotypic diversity in Fabry disease [9]. Urinary $\mathrm{Gb}_{3}$ has been reported to correlate with clinical presentation but is a rather demanding test to perform [36]. Scoring systems, including an age-adjusted scoring system, have been developed to assess the overall severity of Fabry disease and progression over time [37-39], but they are not useful for evaluating ANS activity. Although the sample size of our study does not allow drawing firm conclusions, assessing ANS activity may contribute to comprehensive staging of Fabry disease. If our results are confirmed by larger studies, it may assist in identifying patients at high risk of developing renal and cardiac events, and can be useful tool in non-invasive monitoring of patients on and off treatment.

\section{ACKNOWLEDGEMENTS}

The authors would like to acknowledge the editorial support of Hans Ebels, MD, from Genzyme Corporation. The authors maintain full and independent responsibility for the content of this manuscript.

\section{REFERENCES}

[1] Zarate, Y. and Hopkin, R. (2008) Fabry’s disease. The Lancet, 372, 1427-1435. doi:10.1016/S0140-6736(08)61589-5

[2] Najafian, B., Svarstad, E., Bostad, L., Gubler, M.C., Tondel, C., et al. (2011) Progressive podocyte injury and globotriaosylceramide (GL-3) accumulation in young patients with Fabry disease. Kidney International, 79, 663670. doi:10.1038/ki.2010.484

[3] Ramaswami, U., Najafian, B., Schieppati, A., Mauer, M. and Bichet, D.G. (2010) Assessment of renal pathology and dysfunction in children with Fabry disease. Clinical Journal of the American Society of Nephrology, 5, 365370. doi:10.2215/CJN.08091109

[4] Tondel, C., Bostad, L., Hirth, A. and Svarstad, E. (2008) Renal biopsy findings in children and adolescents with Fabry disease and minimal albuminuria. American Journal of Kidney Diseases, 51, 767-776. doi:10.1053/j.ajkd.2007.12.032

[5] Schiffmann, R., Hauer, P., Freeman, B., Ries, M., Scott, L.J., et al. (2006) Enzyme replacement therapy and intraepidermal innervation density in Fabry disease. Muscle \& Nerve, 34, 53-56. doi:10.1002/mus.20550

[6] Wanner, C., Oliveira, J.P., Ortiz, A., Mauer, M., Germain, D.P., et al. (2010) Prognostic indicators of renal disease progression in adults with Fabry disease: Natural history data from the Fabry registry. Clinical Journal of the American Society of Nephrology, 5, 2220-2228. doi:10.2215/CJN.04340510

[7] Kampmann, C., Wiethoff, C.M., Whybra, C., Baehner, F.A., Mengel, E., et al. (2008) Cardiac manifestations of Anderson-Fabry disease in children and adolescents. Acta Paediatrica, 97, 463-469. doi:10.1111/j.1651-2227.2008.00700.x

[8] Breunig, F., Weidemann, F., Strotmann, J., Knoll, A. and Wanner, C. (2006) Clinical benefit of enzyme replacement therapy in Fabry disease. Kidney International, 69, 1216-1221. doi:10.1038/sj.ki.5000208

[9] Schiffmann, R., Waldek, S., Benigni, A. and Auray-Blais, C. (2010) Biomarkers of Fabry disease nephropathy. Clinical Journal of the American Society of Nephrology, 5, 360-364. doi:10.2215/CJN.06090809

[10] Wilcox, W.R., Oliveira, J.P., Hopkin, R.J., Ortiz, A., Banikazemi, M., et al. (2008) Females with Fabry disease frequently have major organ involvement: Lessons from the Fabry registry. Molecular Genetics and Metabolism, 93, 112-128. doi:10.1016/j.ymgme.2007.09.013

[11] Cable, W.J., Kolodny, E.H. and Adams, R.D. (1982) Fabry disease: Impaired autonomic function. Neurology, 32, 498-502. doi:10.1212/WNL.32.5.498

[12] Dutsch, M., Marthol, H., Stemper, B., Brys, M., Haendl, 
T., et al. (2002) Small fiber dysfunction predominates in Fabry neuropathy. Journal of Clinical Neurophysiology, 19, 575-586. doi:10.1097/00004691-200212000-00011

[13] Hilz, M.J., Marthol, H., Schwab, S., Kolodny, E.H., Brys, M., et al. (2010) Enzyme replacement therapy improves cardiovascular responses to orthostatic challenge in Fabry patients. Journal of Hypertension, 28, 1438-1448. doi:10.1097/HJH.0b013e328336a077

[14] Pintos-Morell, G. and Beck, M. (2009) Fabry disease in children and the effects of enzyme replacement treatment. European Journal of Pediatrics, 168, 1355-1363. doi:10.1007/s00431-009-0937-9

[15] Lidove, O., West, M.L., Pintos-Morell, G., Reisin, R., Nicholls, K., et al. (2010) Effects of enzyme replacement therapy in Fabry disease-A comprehensive review of the medical literature. Genetics in Medicine, 12, 668-679. doi:10.1097/GIM.0b013e3181f13b75

[16] Schaefer, R.M., Tylki-Szymanska, A. and Hilz, M.J. (2009) Enzyme replacement therapy for Fabry disease: A systematic review of available evidence. Drugs, 69, 21792205. doi:10.2165/11318300-000000000-00000

[17] Ortiz, A., Oliveira, J.P., Wanner, C., Brenner, B.M., Waldek, S., et al. (2008) Recommendations and guidelines for the diagnosis and treatment of Fabry nephropathy in adults. Nature Reviews Nephrology, 4, 327-336. doi:10.1038/ncpneph0806

[18] Weidemann, F., Linhart, A., Monserrat, L. and Strotmann, J. (2010) Cardiac challenges in patients with Fabry disease. International Journal of Cardiology, 141, 3-10. doi:10.1016/j.ijcard.2009.08.002

[19] Malik, M. (1996) Heart rate variability: Standards of measurement, physiological interpretation and clinical use. Task force of the European society of cardiology and the North American society of pacing and electrophysiology. Circulation, 93, 1043-1065.

[20] Pichot, V., Gaspoz, J.M., Molliex, S., Antoniadis, A., Busso, T., et al. (1999) Wavelet transform to quantify heart rate variability and to assess its instantaneous changes. Journal of Applied Physiology, 86, 1081-1091.

[21] Cerutti, C., Barres, C. and Paultre, C. (1994) Baroreflex modulation of blood pressure and heart rate variabilities in rats: Assessment by spectral analysis. American Journal of Physiology, 266, H1993-H2000.

[22] Akselrod, S., Gordon, D., Ubel, F.A., Shannon, D.C., Berger, A.C., et al. (1981) Power spectrum analysis of heart rate fluctuation: A quantitative probe of beat-to-beat cardiovascular control. Science, 213, 220-222. doi:10.1126/science.6166045

[23] Pagani, M., Lombardi, F., Guzzetti, S., Rimoldi, O., Furlan, R., et al. (1986) Power spectral analysis of heart rate and arterial pressure variabilities as a marker of sympatho-vagal interaction in man and conscious dog. Circulation Research, 59, 178-193.

[24] Parlow, J., Viale, J.P., Annat, G., Hughson, R. and Quintin, L. (1995) Spontaneous cardiac baroreflex in humans. Comparison with drug-induced responses. Hypertension, 25, 1058-1068.

[25] Bavanandan, S., Ajayi, S., Fentum, B., Paul, S.K., Carr,
S.J., et al. (2005) Cardiac baroreceptor sensitivity: A prognostic marker in predialysis chronic kidney disease patients? Kidney International, 67, 1019-1027. doi:10.1111/j.1523-1755.2005.00165.x

[26] Blankestijn, P.J. (2004) Sympathetic hyperactivity in chronic kidney disease. Nephrology Dialysis Transplantation, 19, 1354-1357. doi:10.1093/ndt/gfh242

[27] Foley, R.N., Parfrey, P.S. and Sarnak, M.J. (1998) Clinical epidemiology of cardiovascular disease in chronic renal disease. American Journal of Kidney Diseases, 32, S112-S119. doi:10.1053/ajkd.1998.v32.pm9820470

[28] Furuland, H., Linde, T., Englund, A. and Wikstrom, B. (2008) Heart rate variability is decreased in chronic kidney disease but may improve with hemoglobin normalization. Journal of Nephrology, 21, 45-52.

[29] Koomans, H.A., Blankestijn, P.J. and Joles, J.A. (2004) Sympathetic hyperactivity in chronic renal failure: A wakeup call. Journal of the American Society of Nephrology, 15, 524-537. doi:10.1097/01.ASN.0000113320.57127.B9

[30] Masuo, K., Lambert, G.W., Esler, M.D., Rakugi, H., Ogihara, T., et al. (2010) The role of sympathetic nervous activity in renal injury and end-stage renal disease. Hpertension Research, 33, 521-528. doi:10.1038/hr.2010.35

[31] Bigger, J.T. Jr., Fleiss, J.L., Steinman, R.C., Rolnitzky, L.M., Kleiger, R.E., et al. (1992) Frequency domain measures of heart period variability and mortality after myocardial infarction. Circulation, 85, 164-171.

[32] Tsuji, H., Larson, M.G., Venditti, F.J. Jr., Manders, E.S., Evans, J.C., et al. (1996) Impact of reduced heart rate variability on risk for cardiac events. The Framingham Heart Study. Circulation, 94, 2850-2855.

[33] Kleiger, R.E., Miller, J.P., Bigger, J.T. Jr. and Moss, A.J. (1987) Decreased heart rate variability and its association with increased mortality after acute myocardial infarction. American Journal of Cardiology, 59, 256-262. doi:10.1016/0002-9149(87)90795-8

[34] Rombach, S.M., Twickler, T.B., Aerts, J.M., Linthorst, G.E., Wijburg, F.A., et al. (2010) Vasculopathy in patients with Fabry disease: Current controversies and research directions. Molecular Genetics and Metabolism, 99, 99-108. doi:10.1016/i.ymgme.2009.10.004

[35] Biegstraaten, M., van Schaik, I.N., Wieling, W., Wijburg, F.A. and Hollak, C.E. (2010) Autonomic neuropathy in Fabry disease: A prospective study using the Autonomic Symptom Profile and cardiovascular autonomic function tests. BMC Neurology, 10, 38. doi:10.1186/1471-2377-10-38

[36] Auray-Blais, C., Cyr, D., Ntwari, A., West, M.L., CoxBrinkman, J., et al. (2008) Urinary globotriaosylceramide excretion correlates with the genotype in children and adults with Fabry disease. Molecular Genetics and $\mathrm{Me}$ tabolism, 93, 331-340.

doi:10.1016/j.ymgme.2007.10.001

[37] Beck, M. (2006) The Mainz Severity Score Index (MSSI): Development and validation of a system for scoring the signs and symptoms of Fabry disease. Acta Paediatrica, 95, 43-46. doi: 10.1111/j.1651-2227.2006.tb02388.x

[38] Giannini, E.H., Mehta, A.B., Hilz, M.J., Beck, M., Bichet, 
D.G., et al. (2010) A validated disease severity scoring system for Fabry disease. Molecular Genetics and Metabolism, 99, 283-290.

doi:10.1016/j.ymgme.2009.10.178
[39] Hughes, D.A., Ramaswami, U., Barba Romero, M.A. and Deegan, P. (2010) Age adjusting severity scores for Anderson-Fabry disease. Molecular Genetics and Metabolism, 101, 219-227. doi:10.1016/j.ymgme.2010.06.002 